\title{
BLS ERC Certified Greek Providers' Willingness to Perform CPR and Skill Retention During the Covid- 19 Pandemic. A Survey of the Hellenic Society of Cardiology (WG CPR)
}

George Latsios ( $\nabla$ glatsios@gmail.com )

National and Kapodistrian University of Athens - Faculty of Medicine https://orcid.org/0000-00029133-9258

Andreas Synetos

G.N.A. Ippokráteio: Geniko Nosokomeio Athenon Ippokrateio

Marianna Leopoulou

Athens General Hospital Elpis

Evaggelia Stamatopoulou

Panepistemiako Geniko Nosokomeio Attikon

Panagiotis Koukopoulos

EMT Greece

Charalambos Parisis

404 Military Hospital

\section{Antonios Karanasos}

G.N.A. Ippokráteio: Geniko Nosokomeio Athenon Ippokrateio

\section{Paraskevi Fragkou}

Evaggelismos General Hospital: Geniko Nosokomeio Athenon O Euangelismos

Konstantinos Toutouzas

G.N.A. Ippokráteio: Geniko Nosokomeio Athenon Ippokrateio

John Kanakakis

GNA Alexandra: Geniko Nosokomeio Athenon Alexandra

Kostas Tsioufis

G.N.A. Ippokráteio: Geniko Nosokomeio Athenon Ippokrateio

Original research

Keywords: BLS ERC certified, cardiopulmonary resuscitation (CPR), Covid-19 pandemic, Hellenic Society of Cardiology, survey, WG CPR

Posted Date: July 8th, 2021 
DOI: https://doi.org/10.21203/rs.3.rs-675780/v1

License: (c) (1) This work is licensed under a Creative Commons Attribution 4.0 International License. Read Full License 


\section{Abstract}

Objective: The aim of this study was to evaluate a. the level of established knowledge regarding cardiopulmonary resuscitation (CPR) during the Covid-19 pandemic era of certified Basic Life Support (BLS) providers and $\mathrm{b}$. their attitude towards CPR, along with possible misconceptions regarding Covid19.

Methods: Certified BLS providers from courses held in Athens, Greece were asked to complete an electronic survey regarding their knowledge and behavioral changes on performing CPR on victims with confirmed or suspected Covid-19 infection. Their perception on BLS courses was also assessed. Answers were collected during June 2020.

Results: Out of 5513 certified providers, $25.53 \%$ completed the survey. The majority (83.36\%) would provide CPR to an arrest victim with possible or confirmed Covid-19 infection. Regarding the use of an automated external defibrillator, the majority thinks that it is equally safe as in the pre-Covid-19 period $(58.24 \%)$. Older age $(<0.001)$ and a lower level of education $(p<0.001)$ made rescuers more willing to provide CPR. Exposure to the European Resuscitation Council $(E R C)(p<0.001)$ and to a lesser degree to Greek National Public Health Organization (NPHO) guidelines was also correlated to a less negative attitude towards resuscitation, whereas time since the last BLS seminar had no such impact $(p=0.18)$. All responders agree that training in CPR during Covid-19 remains necessary.

Conclusion: Certified BLS providers maintain willingness to perform CPR in unresponsive victims even during the Covid-19 pandemic era. This attitude is reinforced by exposure to the updated CPR guidelines. Knowledge regarding Covid-19 CPR is satisfactory, with more training focused on the revised algorithms considered essential.

\section{Introduction}

The evolving and expanding outbreak of the Covid-19 pandemic creates challenges regarding resuscitation efforts and requires potential modifications of established processes and protocols. With the Covid-19 incidence currently increasing exponentially worldwide, the percentage of cardiac arrests of patients with Covid-19 are also likely to increase. Under ordinary circumstances, cardiopulmonary resuscitation (CPR) is always provided unless a patient has a signed do-not-resuscitate order. CPR bares no life-threatening hazard for the providers. However, during the Covid-19 era, providers face risks related to aerosolized transmission of the coronavirus, during the CPR procedure ${ }^{1}$.

The possible risk of infection with Covid-19 of the CPR providers, has led many national societies and international resuscitation councils to publish updated guidelines regarding CPR in order to assist and guide rescuers in treating victims of cardiac arrest with suspected or confirmed Covid-192, 3 . These updates have also been incorporated in the curriculum of the training courses for new providers and are presented as hallmarks of the new era guidelines. 
Currently, the natural history of out-of-hospital cardiac arrest (OHCA) during Covid-19 is being defined by countries with high prevalence of the disease and overwhelmed healthcare services ${ }^{4-8}$. Italy experienced a $58 \%$ increase in OHCA incidence compared to 2019 but most importantly a $15 \%$ increase in mortality; $77.4 \%$ of the increase corresponds to cases directly associated with the Covid-19 infection ${ }^{9}$. Similarly New York had a 6-fold increase in unsuccessful OHCA CPR ${ }^{9}$ while in Paris, the percentage of patients who had an OHCA and were admitted to the hospital alive decreased from $22.8-12.8 \%{ }^{10}$. These decreased rates of successful resuscitation during the pandemic period, indicate that paramedics or bystanders tend to be less aggressive in their resuscitation attempts, possibly due to the reluctance, in both the decision making and the effectiveness, deriving from the fear of a possible Covid-19 infection.

The aim of this study was to evaluate the level of knowledge of Basic Life Support (BLS) providers in relation to the time elapsed from the course, evaluate the changes in the attitude along with possible misconceptions regarding Covid-19-related CPR, conceptualize their attitude towards the course in the Covid-19 era and assess their knowledge and perception on current updated protocols published by the European Resuscitation Council (ERC) and the national societies.

\section{Methods}

\section{Setting and participants}

Certified BLS providers from 210 BLS training events held in Athens, Greece organized by the Cardiopulmonary Resuscitation Working Group of the Hellenic Society of Cardiology (HSC) in collaboration with the ERC during the past 3 years, were asked to complete an electronic survey regarding their knowledge and behavioral changes on performing CPR in victims with confirmed or suspected Covid-19 infection. Following the outbreak of Covid-19 pandemic the participants accessed a web-based survey tool containing questions regarding current knowledge, willingness to perform CPR and implementation in clinical practice of the updated guidelines regarding resuscitation of a victim with suspected Covid-19 infection. The project was funded by the Hellenic Cardiological Society. The providers were exposed to the new protocols through their own responsibility and effort along with webinars, newsletters, and consensus documents derived mainly from the HCS. The questionnaire was sent out on late May 2020 and the answers were gathered from June 1st 2020 until June 21st 2020.

\section{Questionnaire}

The survey was developed by the authors after several focus group sessions and was agreed on by the members of the working group of CPR of the HCS; it consisted of 18 multiple choice questions. Besides demographic information, the participants were asked about their level of education and professional status as well as their working place. Prior CPR training and the time interval from the last BLS seminar were of importance, while the rest of the questions were targeted to the Covid-19 pandemic, examining the effect of the new pandemic on their reaction when confronted with a cardiac arrest victim (proper 
application of all personal protection measures (PPE), role of automated external defibrillator (AED), and significance of CPR training during the pandemic). Finally, the participants were asked whether the training is realistic and can be safely applied in practice, as well as if they were aware about the updated guidelines and associated webinars issued by the ERC and the HCS. The full questionnaire is available in the Appendix.

We tried to establish which of the factors enquired in the questionnaire, had a favorable effect on this appropriate stance of the BLS providers. Also, we tried to establish if a favorable attitude could be attributed to the BLS provider having knowledge of the ERC guidelines or the local instructions (in Greece communicated by the HCS/ NPHO). Lastly, a connection between the actual act of CPR and the opinion of each responder towards the ERC guidelines was pursued.

Survey completion was voluntary, and no incentive was offered. No identifying information was collected from the participants. The study was approved by the institutional scientific committee.

\section{Statistical analysis}

All statistical analyses were performed by MedCalc Statistical Software version 15.8 (MedCalc Software bvba, Ostend, Belgium) Categorical data are expressed as frequencies and group percentages. Possible association of the various variables (demographics, attitude towards Covid19 CPR, attitude towards CPR training) was assessed, to check if there is a relationship between answers to the various questions. Chisquared (crosstabs) test was performed on a null-hypothesis level of $p=0.05$.

\section{Results}

\section{Responders' characteristics}

Out of the 5513 certified providers, $1408(25.53 \%)$ answered the survey and of those 1199 participants (78.80\%) completed all survey questions. Respondents were predominantly female $(67.29 \%)$ and university-educated $(56.12 \%)$. Most of them $(53.04 \%)$ were healthcare workers, the majority being nurses (34.59\%). Out of the 1021 healthcare workers, 202 (19.78\%) were working in nursing wards, 130 (12.73\%) in medical offices or labs and $211(20.6 \%)$ in operating rooms, intensive care units or emergency departments. All had previous BLS training. 536 responders $(38.48 \%)$ had attended the BLS course $1-2$ years ago and 256 participants (18.38\%) $2-3$ years ago. (Table 2 ) 
Table 1

Eligible participants' demographics. Provided is the number of responders to each answer and the corresponding percentage (in parenthesis) to the total population of people that answered the specific question

\begin{tabular}{|ll|}
\hline $\begin{array}{l}\text { gender } \\
\text { male }\end{array}$ & $\begin{array}{l}\text { responders } \\
\text { (percentage) }\end{array}$ \\
\hline female & $456(32.7 \%)$ \\
age (years) & $938(67.3 \%)$ \\
\hline$<18$ & \\
\hline $18-24$ & $21(1.50 \%)$ \\
\hline $25-34$ & $327(23.36 \%)$ \\
\hline $35-44$ & $303(21.64 \%)$ \\
\hline $45-54$ & $373(26.64 \%)$ \\
\hline$>55$ & $300(21.43 \%)$ \\
\hline educational level & $76(5.43 \%)$ \\
\hline elementary, high school & $469(33.50 \%)$ \\
\hline college & $226(16.18 \%)$ \\
\hline university & $784(56.12 \%)$ \\
\hline master's degree & $543(24.55 \%)$ \\
\hline PhD degree & $60(4.29 \%)$ \\
\hline profession & $475(34.37 \%)$ \\
\hline medical doctor & $226(16.35 \%)$ \\
\hline registered nurse & $478(34.59 \%)$ \\
\hline paramedic & $29(2.10 \%)$ \\
\hline teacher & $90(6.51 \%)$ \\
\hline police- /fire- person & $84.08 \%)$ \\
\hline other & \\
\hline
\end{tabular}




\begin{tabular}{|ll|}
\hline \multicolumn{1}{|l}{} & $\begin{array}{l}\text { responders } \\
\text { (percentage) }\end{array}$ \\
\hline $\begin{array}{l}\text { working place } \\
\text { (for health professionals) }\end{array}$ & \\
\hline ICU/CCU & $95(9.30 \%)$ \\
\hline emergency department & $66(6.46 \%)$ \\
\hline operating room & $50(4.90 \%)$ \\
\hline nursing ward & $202(19.78 \%)$ \\
\hline private practice/ laboratory & $130(12.73 \%)$ \\
\hline pre-hospital care & $128(12.54 \%)$ \\
\hline other & $350(34.28 \%)$ \\
\hline
\end{tabular}


Table 2

Specific attitude factors of the providers and attitude towards training of the providers. Given is the number of responders to each answer and the corresponding percentage (in parenthesis) to the total population of people that answered the specific question

responders

(percentage)

\section{Specific attitude factors}

Time elapsed since last certified BLS/ERC/ HCS seminar

$<3$ months

$29(2.08 \%)$

3-6 months

101 (7.25\%)

6-12 months

362

(25.99\%)

$1-2$ years

536

(38.48\%)

2-3 years

256

(18.38\%)

$>3$ years

109 (7.82\%)

How do you believe the ongoing covid-19 pandemic will affect your response when witnessing a cardiac arrest?

Positive -

more confident

Neutral -

as always

Negative -

I don't want to risk infection

What will you do in the case of a cardiopulmonary arrest?

Perform chest compressions without rescue breaths,

without delay for the PPE

Apply and use PPE

regardless of the time delay

Avoid getting involved

$14(1.17 \%)$

Do you believe that performing CPR on a person of your close circle (e.g., at home, at work etc.) with whom you spend a lot of time, essentially increases your chances of contacting Covid-19? 


\begin{tabular}{|c|c|}
\hline & $\begin{array}{l}\text { responders } \\
\text { (percentage) }\end{array}$ \\
\hline Yes & $\begin{array}{l}237 \\
(19.80 \%)\end{array}$ \\
\hline No & $\begin{array}{l}960 \\
(80.20 \%)\end{array}$ \\
\hline \multicolumn{2}{|l|}{$\begin{array}{l}\text { Automated External Defibrillation (AED) use on a cardiac arrest victim during the } \\
\text { pandemic }\end{array}$} \\
\hline $\begin{array}{l}\text { It is as safe as } \\
\text { in the pre-Covid- } 19 \text { period }\end{array}$ & $\begin{array}{l}663 \\
(58.24 \%)\end{array}$ \\
\hline $\begin{array}{l}\text { It is a clear transmission hob } \\
\text { of dangerous airborne droplets }\end{array}$ & 107 (8.99\%) \\
\hline $\begin{array}{l}\text { It is safe only if } \\
\text { the CPR providers stands at least } 2 \text { meters away during the shock } \\
\text { Attitude towards } \\
\text { training }\end{array}$ & $\begin{array}{l}390 \\
(32.77 \%)\end{array}$ \\
\hline $\begin{array}{l}\text { CPR training (basic life support - BLS) during the Covid-19 pandemic is realistic and } \\
\text { can be safely applied in practice }\end{array}$ & \\
\hline $\begin{array}{l}\text { No - } \\
\text { it is not possible to apply all precautions in a situation of crowding and physical } \\
\text { contact }\end{array}$ & 71 (5.93\%) \\
\hline $\begin{array}{l}\text { Yes - } \\
\text { seminars should and must take place like as before, but with all necessary } \\
\text { precautions (correct training) }\end{array}$ & $\begin{array}{l}680 \\
(56.81 \%)\end{array}$ \\
\hline $\begin{array}{l}\text { Yes - } \\
\text { but modifications need to be made (less time -fewer people - distance learning) }\end{array}$ & $\begin{array}{l}446 \\
(37.26 \%)\end{array}$ \\
\hline $\begin{array}{l}\text { Are you aware that the ERC has issued guidelines for modifying resuscitation process } \\
\text { during the Covid- } 19 \text { pandemic and for using personal protective equipment? }\end{array}$ & \\
\hline $\begin{array}{l}\text { Yes, } \\
\text { and I have read them }\end{array}$ & $\begin{array}{l}209 \\
(17.45 \%)\end{array}$ \\
\hline $\begin{array}{l}\text { Yes, } \\
\text { but I have not read them }\end{array}$ & $\begin{array}{l}333 \\
(27.80 \%)\end{array}$ \\
\hline
\end{tabular}




\begin{tabular}{|c|c|}
\hline & $\begin{array}{l}\text { responders } \\
\text { (percentage) }\end{array}$ \\
\hline No & $\begin{array}{l}656 \\
(54.76 \%)\end{array}$ \\
\hline \multicolumn{2}{|c|}{$\begin{array}{l}\text { Are you aware that the Greek National Public Health Organization (NPHO), in } \\
\text { collaboration with HCS (Hellenic Cardiological Society), has published official } \\
\text { instructions for CPR practice during the Covid-19 pandemic? }\end{array}$} \\
\hline $\begin{array}{l}\text { Yes, } \\
\text { and I have read them }\end{array}$ & $\begin{array}{l}227 \\
(18.50 \%)\end{array}$ \\
\hline $\begin{array}{l}\text { Yes, } \\
\text { but I have not read them }\end{array}$ & $\begin{array}{l}346 \\
(28.20 \%)\end{array}$ \\
\hline No & $\begin{array}{l}654 \\
(53.30 \%)\end{array}$ \\
\hline \multicolumn{2}{|c|}{$\begin{array}{l}\text { Are you aware of the ERC web seminar on "Practice of Resuscitation during the Covid- } \\
19 \text { pandemic"? }\end{array}$} \\
\hline Yes & $\begin{array}{l}205 \\
(17.08 \%)\end{array}$ \\
\hline No & $\begin{array}{l}995 \\
(82.92 \%)\end{array}$ \\
\hline \multicolumn{2}{|l|}{$\begin{array}{l}\text { What is your opinion on } \\
\text { the official CPR ERC guidelines? }\end{array}$} \\
\hline $\begin{array}{l}\text { Clear - } \\
\text { concise }\end{array}$ & $\begin{array}{l}127 \\
(17.40 \%)\end{array}$ \\
\hline $\begin{array}{l}\text { Clear - } \\
\text { but have not been adequately communicated }\end{array}$ & $\begin{array}{l}339 \\
(46.44 \%)\end{array}$ \\
\hline $\begin{array}{l}\text { Unclear - } \\
\text { complicated }\end{array}$ & 24 (3.29\%) \\
\hline $\begin{array}{l}\text { Extensive practice is needed } \\
\text { before applying them }\end{array}$ & $\begin{array}{l}264 \\
(36.16 \%)\end{array}$ \\
\hline $\begin{array}{l}\text { I don't agree with these instructions } \\
\text { (safety issues) }\end{array}$ & $12(1.64 \%)$ \\
\hline $\begin{array}{l}\text { Additional training in CPR during Covid-19: ... } \\
\text { it should include... }\end{array}$ & \\
\hline
\end{tabular}




\begin{tabular}{|ll|}
\hline & $\begin{array}{l}\text { responders } \\
\text { (percentage) }\end{array}$ \\
\hline more online training videos & 661 \\
& $(56.98 \%)$ \\
\hline more online training lectures & 315 \\
\hline more online seminars & $(27.16 \%)$ \\
\hline more live (face to face) seminars & 485 \\
& $(40.09 \%)$ \\
\hline
\end{tabular}

\section{Attitude towards providing CPR}

Regarding the attitude and reaction when confronted with a cardiac arrest victim in the Covid-19 era, a total of 997 responders $(83.36 \%)$ answered that they will provide CPR to an arrest victim with possible or confirmed Covid-19 infection; 856 (71.57\%) answered that their behavior would be rather neutral, without changing anything on their response compared to their training and $141(11.79 \%)$ that they would be even more confident to provide CPR (Table 2). Most of the responders ( $n=662,53.35 \%)$ answered that they would immediately start and continue chest compressions without rescue breaths, without delay for the PPE, and 520 responders (43.48\%), answered that they would apply all PPE regardless of the time delay. Moreover, only 237 responders (19.80\%) think that CPR on a person of their close environment with whom they are already in close social contact for hours, substantially increases their chance of infection.

Regarding the use of an AED in the event of a Covid-19 related cardiac arrest, most providers $(n=693$, $58.24 \%)$ think that it is as safe as the use in the pre-Covid-19 period, while 390 responders $(32.77 \%)$, answered that it is safe only if the CPR providers stand at least 2 meters away during the shock, and 107 $(8.99 \%)$ believe that it is a clear source of transmission of dangerous airborne droplets. (Table 2)

\section{Training}

The majority of the certified BLS providers that answered (94.07\%) strongly believes that BLS training during the Covid-19 pandemic is realistic and can be safely applied in practice. However, less than half of the responders (542 persons, $45.24 \%$ ) knew that the ERC issued guidelines for modifying the resuscitation process during the Covid-19 pandemic and less than one-fifth (205 responders, $17.08 \%$ ) were aware of the ERC web seminar on "Practice of Resuscitation during the Covid-19 pandemic", with only 68 (5.69\%) having participated in the specific course.. Regarding local information by official organizations, 556 responders (46.41\%) were aware that the Greek National Public Health Organization has issued official instructions for CPR during the Covid-19 pandemic, in collaboration with the HCS. Accordingly, 339 participants (46.44\%) believe that the updated CPR guidelines are clear but have not 
been adequately communicated, while 264 responders (36.16\%) believe that extensive training is needed before applying them.

As already stated, an important finding is that the majority of the already certified BLS instructors favors further seminars, despite the nature of the SARS-CoV-2 virus and its mode of transmission in proximity. Seminars can and should be conducted as before but with complete precautions (proper instructor training) according to $56.81 \%$, while an additional $37.26 \%$ supports the course conduction only after appropriate modifications (decrease of the seminar duration; division of candidates into smaller groups; application of distal learning in feasible modules). In total, almost all $(94,07 \%)$ believe that BLS training during the Covid-19 pandemic is realistic and can be safely applied in practice, where only a minority of $5.93 \%$ (71 responders) do not complete precautions in crowded conditions and intense physical contact feasible.

Finally, all agreed that additional training in CPR during Covid-19 is necessary and it should be focused mainly on online training videos $(n=661,56.68 \%)$, more live seminars $(n=500,43.10 \%)$, more online seminars $(n=465,40.09 \%)$ and more training lectures $(n=315,27.16 \%)$. (Table 2$)$

\section{Factors affecting the willingness to perform CPR}

As aforementioned, the majority of the responders (83.36\%) were keen to provide CPR to an arrest victim with possible or confirmed Covid-19 infection. This is stated as a response in question (see Appendix) "Attitude towards CPR during Covid-19" with answers ranging from Positive, to Neutral, and finally to Negative. A positive or even neutral approach signifies that the rescuer would indeed provide CPR despite the possibility of an infected with Covid-19 cardiac arrest victim.

The association between rescuers' attitude (and as a result the willingness to perform CPR) and demographics factors is shown in Table 3 . In terms of demographic factors, age group $(p<0.001)$ but not sex had a favorable effect: in regards to age, if we set aside the few juvenile ( $<18$ years old) providers $(14,1.2 \%$ of total responders) of which none had a negative stance towards Covid-19 resuscitation, we found that by increasing age, the percentage of negative answers remained constant at about $15-20 \%$; however as age of the responders' increases, they tend to have more often a positive rather than a neutral stance (Fig. 1). 
Table 3

Factors affecting willingness of officially trained BLS providers to perform CPR during the Covid-19 pandemic period (ie question regarding attitude towards CPR)

\begin{tabular}{|lllll|}
\hline Demographic variables & & & & \\
\hline attitude towards CPR & positive & neutral & negative & p for correlation \\
\hline gender & & & & 0.3672 \\
\hline male & $53(36.55 \%)$ & $280(32.15 \%)$ & $64(31.53 \%)$ & \\
\hline female & $92(63.45 \%)$ & $591(71.45 \%)$ & $139(16.65 \%)$ & \\
\hline age (years) & & & & $0.0002^{\star}$ \\
\hline$<18$ & $4(2.76 \%)$ & $10(1.14 \%)$ & $0(0.00 \%)$ & \\
\hline $18-24$ & $16(11.03 \%)$ & $220(25.14 \%)$ & $45(22.06 \%)$ & \\
\hline $25-34$ & $23(15.86 \%)$ & $201(22.97 \%)$ & $46(22.55 \%)$ & \\
\hline $35-44$ & $50(34.38 \%)$ & $228(26.06 \%)$ & $56(27.45 \%)$ & \\
\hline $45-54$ & $36(24.83 \%)$ & $178(20.34 \%)$ & $45(22.06 \%)$ & \\
\hline$>55$ & $16(11.03 \%)$ & $38(4.34 \%)$ & $12(5.88 \%)$ & \\
\hline educational level & & & & \\
\hline elementary, high school & $47(32.41 \%)$ & $303(34.63 \%)$ & $54(26.47 \%)$ & \\
\hline college & $38(26.21 \%)$ & $123(14.06 \%)$ & $26(12.75 \%)$ & \\
\hline university & $58(40.00 \%)$ & $512(58.51 \%)$ & $124(60.78 \%)$ & \\
\hline master's degree & $35(24.14 \%)$ & $219(25.03 \%)$ & $54(26.47 \%)$ & \\
\hline PhD degree & $9(11.85 \%)$ & $32(71.49 \%)$ & $14(16.67 \%)$ & \\
\hline
\end{tabular}




\begin{tabular}{|c|c|c|c|c|}
\hline profession & & & & 0.2052 \\
\hline medical doctor & $\begin{array}{l}13 \\
(9.29 \%)\end{array}$ & $153(17.67 \%)$ & 32 (15.92\%) & $\begin{array}{l}0.3819 \\
\text { for correlation } \\
\text { among }\end{array}$ \\
\hline registered nurse & $\begin{array}{l}55 \\
(39.29 \%)\end{array}$ & 299 (34.53\%) & $65(32.34 \%)$ & health care workers \\
\hline paramedic & $\begin{array}{l}5 \\
(3.57 \%)\end{array}$ & $17(1.96 \%)$ & $1(0.50 \%)$ & \\
\hline teacher & $\begin{array}{l}9 \\
(6.43 \%)\end{array}$ & $53(6.12 \%)$ & $14(6.97 \%)$ & \\
\hline police- /fire- person & $\begin{array}{l}8 \\
(5.71 \%)\end{array}$ & $53(6.12 \%)$ & $18(8.96 \%)$ & \\
\hline other & 0 & 0 & 0 & \\
\hline $\begin{array}{l}\text { working place (for } \\
\text { health } \\
\text { professionals) }\end{array}$ & & & & \\
\hline ICU/CCU & $\begin{array}{l}13 \\
(11.82 \%)\end{array}$ & $50(7.84 \%)$ & $18(12.77 \%)$ & \\
\hline $\begin{array}{l}\text { emergency } \\
\text { department }\end{array}$ & $\begin{array}{l}9 \\
(8.18 \%)\end{array}$ & $46(7.21 \%)$ & $2(2.13 \%)$ & \\
\hline operating room & $\begin{array}{l}4 \\
(3.64 \%)\end{array}$ & $33(3.17 \%)$ & $10(7.09 \%)$ & \\
\hline nursing ward & $\begin{array}{l}22 \\
(20.00 \%)\end{array}$ & $126(19.75 \%)$ & $29(20.57 \%$ & \\
\hline $\begin{array}{l}\text { private } \\
\text { practice/laboratory }\end{array}$ & $\begin{array}{l}10 \\
(9.09 \%)\end{array}$ & $81(12.70 \%)$ & $19(13.48 \%)$ & \\
\hline pre-hospital care & $\begin{array}{l}16 \\
(14.55 \%)\end{array}$ & 75 (11.76\%) & $18(12.77 \%)$ & \\
\hline other & $\begin{array}{l}26 \\
(32.73 \%)\end{array}$ & 227 (35.58\%) & $44(31.21 \%)$ & \\
\hline $\begin{array}{l}\text { Knowledge and } \\
\text { general attitude } \\
\text { variables }\end{array}$ & & & & \\
\hline $\begin{array}{l}\text { Time elapsed since } \\
\text { last certified BLS/ERC } \\
\text { seminar }\end{array}$ & & & & 0.1773 \\
\hline$<3$ months & $5(3.45 \%)$ & $16(1.84 \%)$ & $2(0.98 \%)$ & \\
\hline $3-6$ months & $16(11.03$ & $59(6.78 \%)$ & $11(5.39 \%)$ & \\
\hline
\end{tabular}




\begin{tabular}{|c|c|c|c|c|}
\hline 6-12 months & 38 (26.21\%) & $224(25.75 \%)$ & 67 (32.84\%) & \\
\hline $1-2$ years & 51 (35.17\%) & 341 (39.20\%) & 78 (38.24\%) & \\
\hline $2-3$ years & 25 (17.24\%) & $168(19.31 \%)$ & $29(14.22 \%)$ & \\
\hline$>3$ years & $10(6.9 \%)$ & $62(7.13 \%)$ & 17 (8.33\%) & \\
\hline $\begin{array}{l}\text { Do you believe that } \\
\text { performing CPR on a } \\
\text { person of your close } \\
\text { circle (eg at home, at } \\
\text { work etc) with whom } \\
\text { you spend a lot of } \\
\text { time, essentially } \\
\text { increases your } \\
\text { chances of } \\
\text { contracting Covid-19? }\end{array}$ & & & & $0.0007 *$ \\
\hline Yes & $32(22.22 \%)$ & 149 (16.99\%) & $59(29.06 \%)$ & \\
\hline No & 112 (77.78\%) & $728(83.01 \%)$ & 144 (70.94\%) & \\
\hline $\begin{array}{l}\text { Are you aware of the } \\
\text { ERC has issued } \\
\text { guidelines for } \\
\text { modifying } \\
\text { resuscitation process } \\
\text { during the Covid-19 } \\
\text { pandemic and for } \\
\text { using personal } \\
\text { protective } \\
\text { equipment? }\end{array}$ & & & & $0.0006^{*}$ \\
\hline $\begin{array}{l}\text { Yes, } \\
\text { and I have read them }\end{array}$ & 38 (26.21\%) & 148 (16.89\%) & $28(13.73 \%)$ & $0.0088 *$ \\
\hline $\begin{array}{l}\text { Yes, } \\
\text { but I have not read } \\
\text { them }\end{array}$ & 49 (33.79\%) & $244(27.85 \%)$ & $50(24.51 \%)$ & \\
\hline No & $58(40.00 \%)$ & $484(55.25 \%)$ & $126(61.76 \%)$ & \\
\hline $\begin{array}{l}\text { Are you aware that } \\
\text { the Greek National } \\
\text { Public Health } \\
\text { Organization (NPHO), } \\
\text { in collaboration with } \\
\text { HCS (Hellenic } \\
\text { Cardiological } \\
\text { Society), has } \\
\text { published official } \\
\text { instructions for CPR } \\
\text { practice during the } \\
\text { Covid-19 pandemic? }\end{array}$ & & & & 0.1049 \\
\hline Yes, & 34 (23.61\%) & 168 (19.18\%) & 25 (12.32\%) & 0.0295 \\
\hline
\end{tabular}


and I have read them

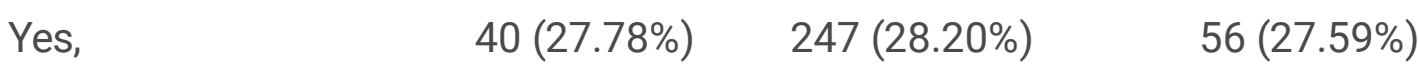

but I have not read

them

No

$70(48.61 \%) \quad 461(52.63 \%)$

$122(16.60 \%)$

Are you aware of the

web ERC seminar

"Resuscitation

practice during the

Covid-19 pandemic"?

$\begin{array}{lcccc}\text { Yes } & 32(22.07 \%) & 160(18.24 \%) & 20(9.80 \%) & 0.3478 \\ \begin{array}{l}\text { Yes, and I have } \\ \text { watched it }\end{array} & 11(7.59 \%) & 52(5.94 \%) & 8(3.98 \%) & 184(90.20 \%) \\ \text { No } & 113(77.93 \%) & 717(81.76 \%) & \end{array}$

What is your opinion on the official ERC CPR

0.3518 guidelines?

\begin{tabular}{|c|c|c|c|}
\hline $\begin{array}{l}\text { Clear - } \\
\text { concise }\end{array}$ & $\begin{array}{l}25 \\
(23.58 \%)\end{array}$ & $\begin{array}{l}87 \\
(16.35 \%)\end{array}$ & $\begin{array}{l}17 \\
(15.32 \%)\end{array}$ \\
\hline $\begin{array}{l}\text { Clear - but have not been } \\
\text { adequately communicated }\end{array}$ & $\begin{array}{l}43 \\
(40.57 \%)\end{array}$ & $\begin{array}{l}260 \\
(48.87 \%)\end{array}$ & $\begin{array}{l}48 \\
(43.24 \%)\end{array}$ \\
\hline $\begin{array}{l}\text { Unclear - } \\
\text { complicated }\end{array}$ & $2(1.89 \%)$ & $21(3.95 \%)$ & $3(2.70 \%)$ \\
\hline $\begin{array}{l}\text { Extensive practice is needed } \\
\text { before applying them }\end{array}$ & $\begin{array}{l}41 \\
(38.68 \%)\end{array}$ & $\begin{array}{l}184 \\
(34.59 \%)\end{array}$ & $\begin{array}{l}46 \\
(41.44 \%)\end{array}$ \\
\hline $\begin{array}{l}\text { I don't agree with these instructions } \\
\text { (safety issues) }\end{array}$ & $1(0.94 \%)$ & $10(1.88 \%)$ & $1(0.90 \%)$ \\
\hline
\end{tabular}

Shown are the number of providers and in parenthesis the proportion (in \%) of providers to the total number of providers that answered the specific question and shared the same attitude towards CPR. ${ }^{*} \mathrm{p}<0.05$ (correlation is statistically significant)

The type of profession in general as well as each one's specific medical profession or working place had no effect on the attitude of the responder; however, the level of education $(p<0.001)$ strongly influenced the approach of certified rescuers. A negative stance towards Covid-19 victims was more often with a higher level of education (Fig. 1). 
The time elapsed from the certified BLS seminar had no impact on the willingness to perform CPR on a Covid-19 victim $(p=0.18)$. Further to this notion, these trained BLS providers that had attended a seminar and had heard of $(p<0.001)$ or even had read $(p<0.01)$ the ERC guidelines had a more positive attitude and would perform CPR on suspected/ confirmed Covid-19 victims of cardiac arrest (Fig. 2). Also, knowledge of the ERC web seminar regarding "Resuscitation during the Covid-19 pandemic" made BLS trained rescuers more eager to respond $(p<0.01)$. To a lesser extent, that did not reach statistical significance, the same conclusions apply to the local, Greek national guidelines (NPHO Greece). Trained BLS providers that were aware of these official statements of the Greek government had a more positive attitude and would therefore perform CPR on suspected/ confirmed Covid-19 victims of cardiac arrest (Table 3 and Fig. 3).

Interestingly, the rescuer's personal viewpoint regarding the guidelines (see details in Appendix) did not influence, in either a positive or a negative manner, his/ her willingness to provide CPR. On the other hand, people that were negatively predisposed towards CPR in the general population during Covid-19, because of fear of self-contamination and subsequent Covid-19 infection, have predictably the same negative stance $(p<0.001)$ even towards a person of the close environment.

\section{Discussion}

Considering the Covid-19 pandemic and the uncertainties around risk of transmission, efforts are needed, pivoting to protect CPR providers and at the same time to ensure that BLS will be provided without hesitation and delay. This two-directional approach must be strengthened through the continuous training of BLS providers with protocols based on the updated algorithms that focus on the safety of the people involved in the CPR.

The most important findings of the study were that in the Covid-19 pandemic era, most BLS providers 1) are confident and willing to provide compressions-only CPR on victims of arrest without applying all the suggested PPE, and 2) are not aware of the ERC web seminar focused on the updated Covid-19 CPR guidelines.

During the first phase of Covid-19 pandemic, ERC discouraged face-to-face, hands-on BLS teaching and mass BLS training and recommended instead individual self-directed learning, apps and Virtual Reality resources $^{11}$. This format was supposed to be very suitable for BLS education for people who wish to master BLS in cardiac arrest and for staying up to date with refresher training. Although this was supposed to reduce the infection risk for both candidates and instructors, the lack of supervision endangered the whole updating process. More importantly the already certified BLS providers were not obliged to update their knowledge and skills, as they hadn't been notified by any official organization or involved in an obligatory renewal online course. Most of the providers were aware of these updates, through scientific papers that had to undergo the peer-review process and then be communicated by local organizations such as the HCS or Greek National Public Health Organization. According to the results, more than half of the participants support the conduction of seminars with complete precautions (proper 
instructor training) while many support the course conduction only after appropriate modifications such as decrease of the seminar duration; division of candidates into smaller groups and application of distal learning in feasible modules. Notably, the ERC has subsequently addressed and applied many of these precautions in the seminar process.

According to our opinion, the most important finding of the study is the determination and willingness of BLS providers to provide CPR on arrest victims during the pandemic era and this is in concordance with previous studies ${ }^{11}$. This shows that the mentality and the basic values of saving a life remain unaffected even in such unprecedented times, as the pandemic did not cause any decrease in the levels of willingness to provide CPR. It seems that the messages and the "good Samaritan" approach regarding resuscitation that are communicated on the official ERC BLS seminars remain constant over time, regardless if the time that has passed is 3 months or 3 years. The necessity of performing compressionsonly CPR is well recognized by the responders, however the application of PPE did not get the appropriate attention. A possible explanation for this is that it has not been clarified whether the time needed for PPE application overcomes the delay in CPR initiation accompanied by the increase of no-flow time of the victim. In fact the most important gap of knowledge is the need of covering the victim's nose and mouth with a mask or cloth, and the use of a surgical mask by the rescuers. The use of AED is well understood in most cases, however, the misconception that it is a clear source of transmission of dangerous airborne droplets and it has to be performed with the providers standing at least 2 meters away during the shock is still prevalent. Despite these discrepancies, it is encouraging that most participants require more online training or well-organized seminars.

In our study, older age and interestingly a more elementary level of education made rescuers more willing to provide CPR in Covid-19 suspected victims. This apparently contradictory finding is in contrast to previous studies in the pre-covid-19 era, and might be explained by the fact that those with more knowledge about resuscitation could be more likely to cite fear of disease of Covid-19 transmission as an obstacle to performing BLS, whereas their counterparts with less knowledge of BLS might not be aware of this possibility ${ }^{12-14}$. Although previous studies have shown that positive attitude and willingness was significantly predicted by the recent completion of BLS training, our study failed to show such a result ${ }^{12}$. This can be explained by the short time interval from their last BLS course as only $7.82 \%$ or the responders had their last BLS course more than 3 years from the time of the survey. Moreover it should be noted, that the percentages of positive attitude participants remain in higher levels compared to those in the pre-Covid-19 studies $^{13,14,15}$. Also, the exposure to the ERC and to a lesser degree to NPHO Greek guidelines was also correlated to a less negative attitude towards resuscitation.

Historically, the possibility of contracting an infectious disease while performing CPR has been a major cause of concern ${ }^{16}$. Similarly, nowadays, the spread of Covid-19 is generating panic across the globe, as new ways to eliminate the human factor in the CPR process are being examined ${ }^{17}$. With the advent of social media-related misinformation, emergency situations requiring immediate bystander interventions, such as cardiac arrest, have been affected. The dangerous combination of fear and misinformation 
might decrease morale along with the willingness to provide help to someone who suddenly collapses in a public place and further drop the rate of bystander-initiated CPR. Although official organizations have proposed and updated their CPR guidelines, it seems that all the new measures have not been adequately communicated. Less than half of the responders knew about the Covid-19 associated ERC guidelines and less than one-fifth were aware of the ERC web seminar on "Practice of Resuscitation during the Covid-19 pandemic", with even fewer participants. This may reflect the fact that the questionnaire was issued shortly after those ERC actions. Further effort focused on multiple forms of communication and online practicing is necessary to overcome this shortcoming.

\section{Limitations}

A possible limitation of our study is the selection bias, as only $25 \%$ of all registered certified BLS providers answered the questionnaire. Also, the study refers to people trained under specific certified official Greek organizations, with a rather great representation of health providers. Few participants underwent BLS training slightly more than 3 years ago but nevertheless were also included, since in an the emergency situation as the Covid-19 pandemic, we felt that their opinion mattered. Furthermore, providers are willing to provide CPR irrespective of the time elapsed since their certification, which varies among European countries from 3 to 5 years.

\section{Conclusion}

Certified BLS providers maintain an increased willingness to perform CPR in unresponsive victims even during the Covid-19 pandemic era, an attitude that is reinforced by exposure to the appropriate CPR guidelines (ERC, local). The level of knowledge regarding CPR during Covid-19 is satisfactory; however, more training focused on the revised algorithms is essential to further increase the motivation and safety of out-of-hospital CPR.

\section{Declarations}

\section{Conflicts of Interest}

None declared

\section{References}

1. van Doremalen N, Bushmaker T, Morris DH, et al. Aerosol and surface stability of HCoV-19 (SARSCoV-2) compared to SARS-CoV-1. medRxiv : the preprint server for health sciencesMar 132020.

2. Latsios G, Synetos A, Mastrokostopoulos A, Vogiatzi G, Bounas P, Nikitas G, Papanikolaou A, Parisis C, Kanakakis I, Goudevenos J. CardioPulmonary Resuscitation in patients with suspected or confirmed Covid-19. A consensus of the Working group on CardioPulmonary Resuscitation of the 
Hellenic Society of Cardiology. Hellenic J Cardiol. 2021 Jan-Feb;62(1):24-28. doi: 10.1016/j.hjc.2020.09.010. Epub 2020 Sep 17.

3. Nolan JP, Monsieurs KG, Bossaert L, et al. European Resuscitation Council COVID-19 guidelines executive summary. ResuscitationAug 2020;153:45-55.

4. Baldi E, Sechi GM, Mare C, et al. Out-of-Hospital Cardiac Arrest during the Covid-19 Outbreak in Italy. The New England journal of medicineJul 30 2020;383:496-498.

5. Baldi E, Sechi GM, Mare C, et al. COVID-19 kills at home: the close relationship between the epidemic and the increase of out-of-hospital cardiac arrests. European heart journalJun 1 2020;41:3045-3054.

6. Lai PH, Lancet EA, Weiden MD, Webber MP, Zeig-Owens R, Hall CB, Prezant DJ. Characteristics Associated With Out-of-Hospital Cardiac Arrests and Resuscitations During the Novel Coronavirus Disease 2019 Pandemic in New York City. JAMA cardiologyJun 192020.

7. Marijon E, Karam N, Jost D, et al. Out-of-hospital cardiac arrest during the COVID-19 pandemic in Paris, France: a population-based, observational study. The Lancet Public healthAug 2020;5:e437e443.

8. Paoli A, Brischigliaro L, Scquizzato T, Favaretto A, Spagna A. Out-of-hospital cardiac arrest during the COVID-19 pandemic in the Province of Padua, Northeast Italy. ResuscitationSep 2020;154:47-49.

9. Baldi E, Sechi GM, Mare C, et al. Treatment of out-of-hospital cardiac arrest in the COVID-19 era: A 100 days experience from the Lombardy region. PloS one2020;15:e0241028.

10. Daily Chart. Deaths from cardiac arrests have surged in New York City.The Economist. (Accessed 14th April 2020 at:. https://www.economist.com/graphic-detail/2020/04/13/deaths-from-cardiacarrests-havesurged-in-new-york-city). The Economist2020.

11. Birkun A. Distant learning of BLS amid the COVID-19 pandemic: Influence of the outbreak on lay trainees' willingness to attempt CPR, and the motivating effect of the training. ResuscitationJul 2020;152:105-106.

12. Abolfotouh MA, Alnasser MA, Berhanu AN, Al-Turaif DA, Alfayez Al. Impact of basic life-support training on the attitudes of health-care workers toward cardiopulmonary resuscitation and defibrillation. BMC health services researchSep 22 2017;17:674.

13. Jelinek GA, Gennat H, Celenza T, O'Brien D, Jacobs I, Lynch D. Community attitudes towards performing cardiopulmonary resuscitation in Western Australia. ResuscitationDec 2001;51:239-246.

14. Johnston TC, Clark MJ, Dingle GA, FitzGerald G. Factors influencing Queenslanders' willingness to perform bystander cardiopulmonary resuscitation. Resuscitation Jan 2003;56:67-75.

15. Latsios G, Synetos A, Leopoulou M, Stamatopoulou E, Vogiatzi G, Parisis C, Papanikolaou A, Kanakakis J, Toutouzas K, Tousoulis D, Tsioufis K; Working Group of Cardiopulmonary Resuscitation of the Hellenic Cardiological Society. Retention of knowledge after basic training in cardiopulmonary resuscitation: a cumulative 3-year experience of certified ERC seminars of the Hellenic Society of Cardiology. Hellenic J Cardiol. 2021 Apr 9:S1109-9666(21)00085-3. doi: 10.1016/j.hjc.2021.04.001. Epub ahead of print. PMID: 33845202 
16. Fragkou P, Dimopoulou D, Latsios G, Koudounis P, Synetos A, Dimopoulou A, Tsioufis K, Papaevangelou V, Tsiodras S. Transmission of infections during cardiopulmonary resuscitation". In print.

17. Latsios, G., Leopoulou, M., Synetos, A., Karanasos, A., Melidi, E., Toutouzas, K., \& Tsioufis, K. (2021). The role of automated compression devices in out-of- and in- hospital cardiac arrest. Can we spare rescuers' hands? Emergency Care Journal, 17(2).

\section{Appendix}

Appendix is not available with this version.

\section{Figures}
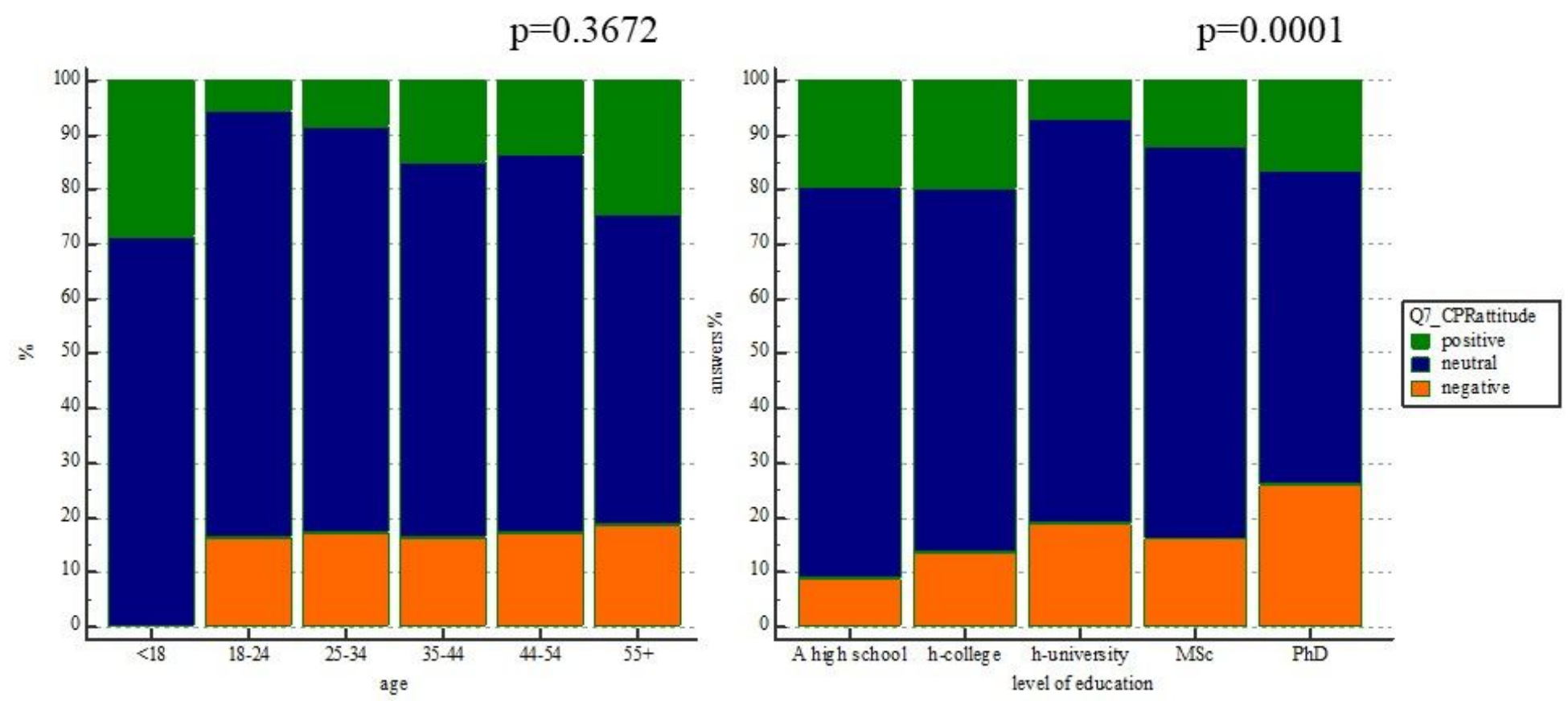

Figure 1

Figure 1 
Attitude towards CPR in a Covid-19 arrested victim, according to the rescuer's age (left) and level of education (right) Positive attitude: green, Neutral attitude: blue, Negative attitude: orange bars $(100 \%$ stacked columns)
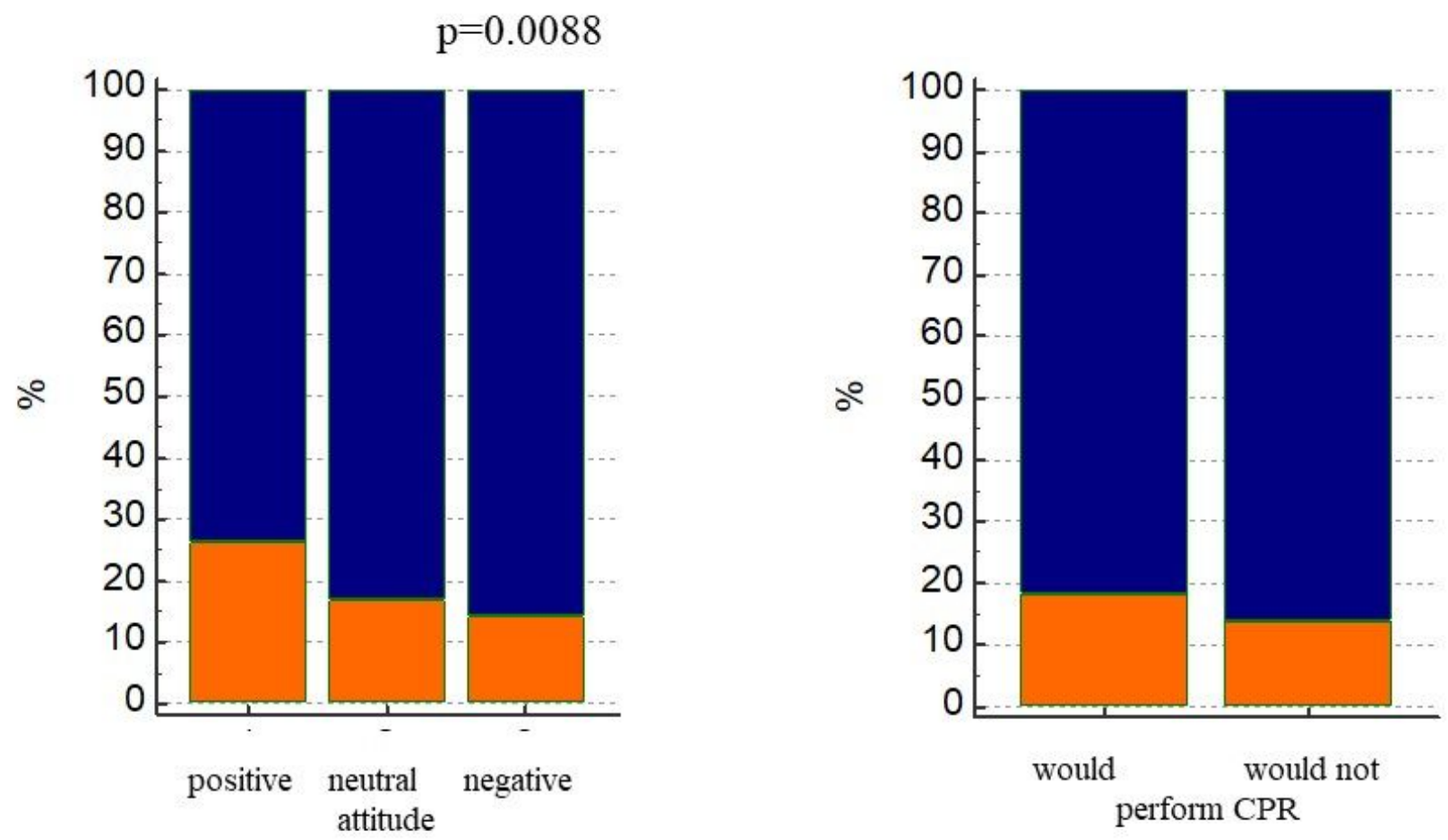

had

had not read "the ERC guidelines on covid19

\section{Figure 2}

\section{Figure 2}

Graphs showing the relative frequency ( $100 \%$ stacked columns) that the responders had (orange) or had not (blue) read "the ERC guidelines regarding resuscitation in the Covid-19 period"; each bar reflects the responder's attitude towards BLS CPR The left graph, regarding Positive / Neutral /Negative attitude towards CPR, when grouped together would eventually lead to the right graph, which showed that the provider would/ would not perform CPR (as a result of the previous question). Trained BLS providers that have read the ERC guidelines had a more positive attitude and would therefore perform CPR in suspected/ confirmed Covid-19 victims of cardiac arrest 

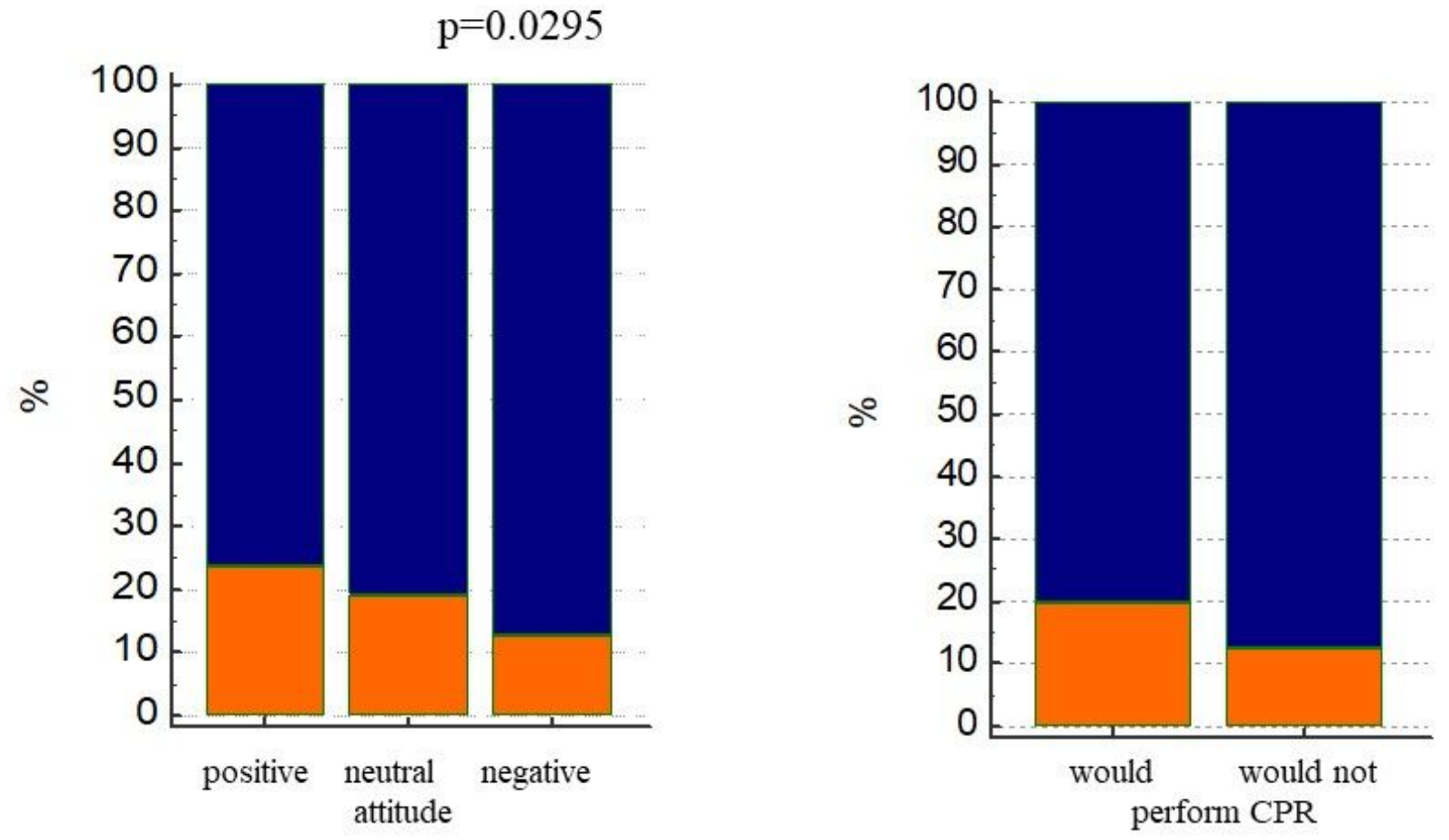

had

had not read "the Greek NPHO guidelines on covid19

Figure 3

\section{Figure 3}

Graphs showing the relative frequency ( $100 \%$ stacked columns) that the responders had (orange) or had not (blue) read "the Greece NPHO instructions regarding resuscitation in the Covid-19 period"; each bar reflects the responder's attitude towards BLS CPR The left graph, regarding Positive / Neutral / Negative attitude towards CPR, when grouped together would eventually lead to the right graph, which showed that the provider would/ would not perform CPR (as a result of the previous question). Trained BLS providers that were aware of these official statement of the Greek government had a more positive attitude and would therefore perform CPR in suspected/ confirmed Covid-19 victims of cardiac arrest 